\title{
DUPLA MENINGOCELE NA COLUNA VERTEBRAL
}

\author{
EHRENFRIED O. WITTIG *
}

A coluna vertebral em seu desenvolvimento embrionário, derivada do mesênquina e envolta por tecido mesodérmico, passa por três fases ${ }^{2,9}$. No estado mesenquimatoso ou membranoso, próximo à terceira semana, o esclerótoma modifica sua estrutura celular, constituindo o arco neural no interior do qual se encontra a corda dorsal. O arco neural progressivamente envolve a medula formando, na porção posterior, apófises que, inicialmente duplas, tendem a se unificar. No segundo mês tem início o periodo cartilaginoso ou de condrificação que se completará ao final do quarto mês. O periodo ósseo, ao término do terceiro mês, principia por um ponto de ossificação no corpo vertebral e dois apofisários que, progressivamente, se aproximam; por ocasião do nascimento estão juntos, mas não totalmente ossificados. Do fechamento das massas espinhosas resultará a apófise espinhosa. O fechamento apofisário tem início na parte cefálica da coluna vertebral. A fusão do tubo neural se inicia do $20^{\circ}$ ao $22 .^{\circ}$ dia e se completa, no polo caudal, aproximadamente no $30 .^{\circ}$ dia. Assim, o período entre o $20 .^{\circ}$ e o $30 .^{\circ}$ dia, corresponde à etapa crítica para as malformações raqueana. Alterações patológicas poderão ocorrer nesta fase do desenvolvimento ${ }^{5,6}$ impedindo a união das massas espinhosas e produzindo espinha bífida. Esta eventualidade poderá associar-se à protusão das meninges (meningocele) que, por sua vez, poderá, ou não, conter elementos nervosos. Esta malformação freqüentemente se associa a outras, motivo pelo qual é incluída no grupo das disrafias. As espinhas bífidas são mais freqüentes nos pontos de transição das curvaturas, podendo ser isoladas ou múltiplas e manifestar-se com ou sem meningocele, em qualquer parte da coluna raqueana. Registramos um caso de dupla meningocele na coluna vertebral.

\section{OBSERVAÇAO}

A. M. L., com dois meses de idade, sexo feminino, branca, internada em 7-6-1963 (R.G. 024.011). Relata a mãe que, ao nascimento, a paciente já apresentava duas tumoraçōes ao nivel da coluna vertebral. Antecedentes - Parto normal a têrmo; entre o $4 .^{\circ}$ e $5 .^{\circ}$ mês de gestação a mãe apresentou hemiparesia esquerda transitória; os pais não são consangüineos. Exame físico — Perímetro cefálico $41 \mathrm{~cm}$; distâncias ântero-posterior $25 \mathrm{~cm}$ e biauricular 23,5 cm. Fontanelas não tensas; a anterior com diâmetros de $10 \times 8 \mathrm{~cm}$ e a posterior com

Trabalho da Clínica Neurológica (Prof. Lacerda Manna) da Faculdade de Medicina da Universidade Federal do Paraná: * Assistente voluntário. 
$5 \times 2 \mathrm{~cm}$. Pequena hérnia inguinal direita redutível; a pele da região cefálica apresenta-se lisa, com veias visíveis; implantação baixa e alargada do nariz. Exame neurológico - Contactuação boa; reflexo patelar esquerdo mais vivo que o direito; marcha reflexa hipoativa; moderada hipotrofia do membro inferior esquerdo, principalmente do pé, o qual se apresenta em eqüino varo. Presença de duas tumoraçoes na coluna vertebral: a superior, ao nivel da coluna torácica alta com $4,5 \mathrm{~cm}$ no maior diâmetro, pediculada, não tensa, a inferior, ao nivel da coluna torácica baixa com $9 \times 7 \mathrm{~cm}$, sem pediculo, com circunferência basal de $17 \mathrm{~cm}$, tensa. Em ambas nada se evidenciou por transiluminação. A meningocele inferior é apenas parcialmente recoberta por pele e mostra, na sua implantação, pelos longos, enquanto que na superior existe apenas penugem escura (fig. 1). Exames complementares - Radiografia da coluna lombo-sacra: hemi-vértebras múltiplas; dupla meningocele, a inferior situada aproximadamente nas duas últimas torácicas. e primeira lombar e, a superior, na última cervical e duas primeiras torácicas. Radiografia do crânio: pequena diástase de suturas e cavalgamento das partes ósseas posteriores. Pneumoventriculografia: dilatação simétrica do sistema ventricular. Evolução - Alguns dias após o exame neuro-radiológico houve aumento brusco dos perímetros cefálicos, ocasiāo em que foi realizada uma drenagem do ventrículo para o peritônio e ressecção da meningocele superior. $O$ caso não teve complementação cirúrgica, por abandono do tratamento.

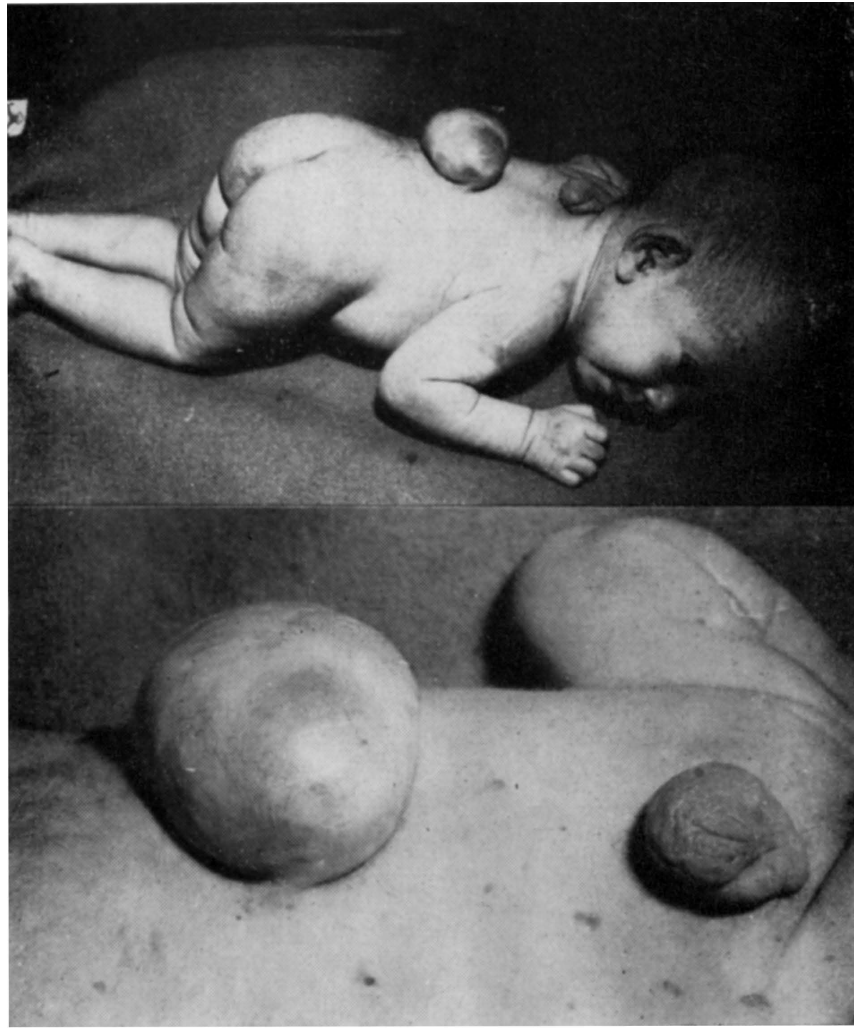

Fig. 1 - Caso A.M.L. Dupla meningocele, sendo a superior pediculada e flácida, $e$ a inferior maior $e$ tensa. Ambas apresentam implantação de pêlos na base. 


\section{COMENTARIOS}

Embora sejam numerosos os trabalhos publicados ${ }^{3,4,7}$ sôbre meningocele, poucos ${ }^{1,8}$ fazem referências a dupla meningocele na coluna vertebral. Bastante conhecida é sua freqüência nos niveis de transição (côncavo-convexo) das curvaturas dos segmentos da coluna e, também, a possibilidade de sua formação em qualquer lado do processo ósseo vertebral e, mesmo, ao nivel do crânio. Muitas vêzes pacientes, aparentemente normais ou com hidrocéfalo compensado, com ou sem tais malformações, apresentam aumento brusco do perímetro cefálico, espontâneamente ou quando submetidos a exames neuroradiológicos ou à cirurgia plástica da meningocele. No caso relatado, dias após a pneumoventriculografia tal fato ocorreu. Para compensar o hidrocéfalo foi decidido fazer a drenagem do líquido cefalorraqueano mediante derivação ventrículo-peritoneal.

\section{RESUMO}

E relatado caso de dupla meningocele de coluna vertebral, respectivamente nas regiões cervico-torácica e tóraco-lombar, no qual ocorreu hidrocéfalo após pneumoventriculografia. Para a compensação do hidrocéfalo foì feita drenagem ventrículo-peritonial.

\section{SUMMARY}

\section{Double spinal meningocele}

A case of double spinal meningocele in thoraxic vertebral column in which occurred hydrocephalus after a pneumo-encephalographic examination is reported. To compensate the hydrocephalus a ventricle-peritoneal derivation was performed.

\section{REFERENCIAS}

1. BRASON, A. J. - Radiological studies of spina bifida cystica. The phenomenon of congenital lumbar kyphosys. Brit. J. Radiol. 38:294, 1965.

2. CANELAS, H. M.; ZACLIS, J. \& TENUTO, R. A. - Contribuiçāo ao estudo das malformações occípito-cervicais. Arq. Neuro-psiquiat. (São Paulo) 10:407, 1952.

3. CAMPBEll, J. - Congenital anomalies of the neural axis. Amer. J. Surg. $75: 231,1948$.

4. DEKABAN, A. - Neurology of Infancy. The Williams \& Wilkins Co., Baltimore, 1959 .

5. FORD, F. R. - Diseases of the Nervous System in Infancy, Childhood and Adolescence. Charles C. Thomas, Springfield (Illinois), 1960. 
6. GAREISO, A. \& ESCARDO, F. - Neuro-Psiquiatria. Editorial El Ateneo, Buenos Aires, 1956.

7. INGRAHAM, F. D. \& MATSON, D. D. - Neurosurgery of Infancy and childhood. Charles C. Thomas, Springfield (Illinois), 1961.

8. SIlva, M. U. M. - Estudo clínico, cirúrgico e ortopédico da raquisquisis. Tese, Rio de Janeiro, 1921.

9. TAURE, M. - Anatomia del Desarrollo. Editorial Científico Médica, Barcelona, 1947.

Hospital de Clínicas - Clínica Neurológica - Curitiba, Paraná - Brasil. 